\title{
Incentive Schemes, Employee Motivation and Productivity In Organizations In Nigeria: Analytical Linkages
}

\author{
*Dr. Ugwu Ude and **Dr. M. A. Coker \\ Institute of Public Policy and Administration \\ University of Calabar, cross River state, Nigeria
}

\begin{abstract}
The paper aims at determining the link between incentive schemes and employee motivation and productivity in organizations and to provide useful information to management on how best to design and administer incentive schemes. To achieve this objective, the paper draws largely from past research findings and cases from the United Nations development Programme (UNDP). Cases cited include those from Tanzania, $R$ wanda and Brazil. The findings were that incentive schemes have high significant relationship with employee motivation and productivity in both the organized private sector and public sector organizations in Nigeria. The paper recommends that management must identify the type of incentive that best motivate the employee, design and administer flexible incentive programmes, seek and obtain feedback on incentives and set effective employee performance goals in the organization.
\end{abstract}

Keywords: Incentive schemes, motivation, employee productivity, reinforcement, analytical linkages, material incentives, and non-material incentives.

\section{Introduction}

Employees occupy a strategic role and position in any organization. They are responsible for converting inputs to productive outputs. Since they are the key to the productive outputs, they ought to be effectively and adequately compensated for their labour. Taking cues first from the Biblical expression that a labourer deserves his wages; and secondly bearing in mind that the reward for labour, a factor of production is "wages", it becomes logical that employees be adequately and fairly compensated if they are to be motivated to increase productivity in any organization be it the organized private sector or public sector.

Drucker (1980:230) believes that "the work of management is to make people productive" so as to achieve superior performance, and gain a competitive edge in the globalized arena through effective compensation packages. Drucker's belif is anchored on productivity, performance, motivation quality and service in managing people in every organization. This emphasis is often captured in organizational mission statements and goals.

Two major components of compensation are open to management: the financial (material) and the nonfinancial (non-material) components. According to Milkovich and Newman (2008) incentive schemes (shortterm and long-term) constitute part of the financial components of employee compensation. Incentive schemes tie pay increase to performance and have been used by organizations worldwide with remarkable success. For example, Niagara Frontier Transit Metro System, Inc, New York uses the safe Driver Awards for bus operators who have experienced accident free driving during the previous year. Recipients are awarded incentives ranging from pins through watches to bonds, extra weeks vacation, and certificates. The incentives are given at an annual luncheon held for recipients. The 'best of the best' incentive is given to employees based on an individuals performance evaluation and extraordinary service in line with the mission statement of Montgomery country division of Transportation Services, Rockville, Maryland, USA. In Thailand, the government offered public doctors incentives to work in rural and remote areas (Hongoro and Normand, 2002).

The Human Development Report, 2001 showed that Korea and Taiwan used incentive schemes to encourage their diasporas to return than encouraging them to invest at home. They upgrade their research institutions as a way to attract returnees. The commissions responsible for this exercise provide better working conditions help with housing and children's schooling.

In Colombia, government attempted to correct the distortionally problems of donor-driven salary top ups and project implementation units and through its "Rectangular Strategy", increased civil service pay between $10-15 \%$ per annum in priority areas. All the incentive schemes as highlighted above motivate employees and fielded positive results on the organizations and the economy. It is believed that if Nigerian organizations too offer effective incentive schemes to their employees, they will be motivated hence increase in productivity. 


\section{Paper Objective}

This paper is meant to provide useful information about incentive schemes and to analyze the link between incentive schemes and employee motivation and productivity in organizations in Nigeria. To accomplish this objective, the remaining part of the paper is organized and presented under the following subheadings: conceptual clarifications, theoretical nexus, employee motivation and productivity, purpose of incentive schemes, employee motivation, productivity, conditions for incentive schemes, caveats for the administration of effective incentive schemes, methodology/approach, paper findings, conclusion and recommendations.

\section{Conceptual clarifications}

Hartman, Kurtzand and Moser (1994) state that incentives are one technique by which employees' carry out their end of the employment contract, that is, compensating employees for their efforts. In general, an incentive scheme (payment or programme) is any compensation that has been designed to recognize some specific accomplishment on the part of an employee. It is expected that the prospect of the incentive payment will 'trigger' the desired performance behaviour in the employee.

Incentive schemes as defined by Graffin and Ebert (1993), are special pay programmes designed to motivate high performance. Incentive schemes attempt to link at least a portion of pay to job performance to encourage higher productivity. Incentives, as often called, should be aligned with the behaviours that help achieve organizational goals or performance. Incentives are either individual or group (organization wide). In this study, financial incentives are designed to motivate employees to improve their performance - to increase effort and output and by producing better results expressed in such terms as objectives for profit, productivity, sales turnover, cost reduction, quality customer service and on time delivery. This financial compensation provides extra money for achievement in terms of contribution or output. The emphasis in financial compensation is on equity, in the sense of paying people according to their just 'deserts'.

Incentive schemes relate compensation to productivity. A primary purpose of an incentive scheme is to encourage greater productivity from individuals and work groups. The assumption usually made by management is that money or cash alone may not motivate employees. In designing incentive schemes, output standards should be established. The standard is a measure of work that an average, well-trained employee, working at a normal pace, should be able to accomplish in a given period of time. In addition to motivating employees to increase their level of productivity, incentive schemes may reduce turnover among good performers or productive workers. Incentive schemes are also cost effective because of savings that often resulted from productivity improvements.

\section{Employee Motivation}

Baron (1991) stated that motivation is the internal processes that activates, guides and maintains behaviour (especially goal directed behaviour). Robertson and Smith (1985) agreed to this statement by observing that motivation is a psychological concept related to the strength and direction of human behaviour. Steers and Porter (1983) had earlier opined that motivation was the arousal, direction and persistence of behaviour while Krech, Crutchfield, \& Ballachey (1962) described motivation as the direction and persistence of action. Motivation is concerned with why people choose a particular course of action in preference to others and why they continued with a chosen action, often over a long period and in the face of difficulties and problems. Mitchell (1982) identified four common characteristics which underlie the definition of motivation to include an individual phenomenon, intentional, multifaceted and prediction of behaviour. Motivation involves efforts, persistence and goals. For this article, Buchanan and Hueznski (2004. 244) definition is preferred as a working definition. They defined motivation as: "The cognitive decision making process through which goal directed behaviour is initiated, energized, directed and maintained". From a manager's perspective, a person who is motivated works hard, sustains a pace of hard work, and has self-directed behaviour toward important goals. When a person's performance is unsatisfactory, low motivation is often considered to be the problem that could affect that person's level of productivity. The underlying concept of motivation is some driving force within individuals by which they attempt to achieve goals in order to fulfill some needs or expectations.

Motivation begins with the realization that individuals have needs or expectations that they want to meet. These needs result in a driving force or behaviour to accomplish desired goals. Accomplishing the desired goals gives a sense of fulfillment or satisfaction which ultimately leads to performance and productivity. Through feedback, employees would modify their needs. Like compensation, motivation is important to employees because they have to be motivated (compensated) to perform at an acceptable level, to do a good job join, and remain with the organization. 


\section{Employee Productivity}

In economics, productivity is the ratio of what is produced to what is required to produce. It is the measure of production efficiency over a given period of time. To the engineer; productivity means new technology, machines and equipment, measurement and controls. To a business manager, productivity has various meanings including effectiveness and efficiency. This is because in management there are no measurable units of output, no productivity function and the non-existence of an effective data base. Agoro (1991) uses the word productivity to mean the output per unit of factor input over a given period of time. It is the ratio between the output of wealth produced and the input of resources consumed in the process of production. Adekoya (1991), agree emphasizing that productivity is a measure of how well labour resources/skills are brought together in a firm and utilized for accomplishing a set result.

Efficiency in production is measured by the ratio of input to output. Efficiency in the utilization of labour in an organization involves obtaining the highest level of performance from the employees with the least expenditure in labour wages. The International Labour Organization (ILO) as cited in Prokopenko (1992) defined productivity to be the effective and efficient utilization of all resources; capital, labour, material, energy, information and time. In this paper, Nwasike's (1991) definition is used, as a working definition. She defined productivity as: 'The efficiency with which inputs are used to produce the desired output'.

Earlier, Udo-Aka (1983) defined productivity as a measure of overall production efficiency, effectiveness and performance of the individual organization. Akerele (1991. 50) contends that productivity is the "measure of how well a nation's resources are utilized for accomplishing a set of results...reaching the highest level of performance with the least expenditure of resources". This is a synthesized definition of productivity. Akerele (1991. 51) further maintained that:

Productivity is an attitude of the mind. It is the mentality of progress and constant improvement of that which exists. It is the certainty of being able to change that which exists. It is the certainty of being able to do better today than yesterday. It is the will to improve on the present situation, no matter how good it may look. It is the constant adaptations of economic conditions. It is the continued effort to apply new techniques and it is the faith in human capabilities.

From the above, it is clear that the applicability of the productivity concept to every sphere of human endeavour remains constant, the relevance and centrality of productivity to human existence can never be denied. This paper assumes that productivity is effectiveness, efficiency, performance and growth.

Productivity improvement, in the words of Prokopenko $(1998$, p. 9) "is not just doing things better. It is doing the right things better". Productivity improvement therefore depends on upon how successfully the main factors of socio-production systems that influence productivity are identified and used. Nworah (1991) had earlier contended that productivity improvement was the increase in output (goods and services) got from a given input by better management and utilization of resources, including human resources. It does not necessary mean getting them to work smarter. Work is generally easier when productivity improvement takes place.

Productivity improvements are obtained through improved product or system design, use of improved machinery and equipment, improved skill and effectiveness of the workers and increased production volume and levels. Productivity improvement is important for this paper because it makes it easier to improve the standard of living of any nation hence its applicability to the Nigerian business situation. Productivity measurement can also be regarded as the quantification of both the output and input resources of a productive system. These outputs and inputs are expressed in mathematical ratio so as to have a quantified monitoring index. Methods of measuring productivity at the company level are the Kurosawa structural method, the Lawler's method, the Gold method, and the quick productivity method.

Other productivity improvement techniques include the following: work study, method study, work measurement, work simplifications, parents analysis, just-in-time method, management through value analysis, cost benefit analysis, zero-based budgeting, cost-productivity allocation, process, organizational development (OD) processes and techniques, brainstorming, forced field analysis, nominal group techniques, and so on, Mali (1981) and Moss (1982). ILO (1985), Welliegh, (1986).

\section{Theoretical Nexus}

Theories surrounding compensation may range from equity/justice theory, expectancy theory, agency theory to tournament and human capital theories. For this paper, Skinner's (1974) reinforcement theory is relevant. The reinforcement approach to employee motivation sidesteps the issues of employee needs and the thinking processes. It simply considers the relationship between behaviour and its consequences and focuses on changing or modifying the employees' on the job behaviour through appropriate use of immediate incentives (rewards). The paper emphasizes positive reinforcement: the administration of a pleasant and rewarding consequence following a desired behaviour. To recognize an employee who arrives on time or does little extra in his work is a good example of positive reinforcement. The likelihood of the employee continuing with the excellent behaviour is what Skinner called 'the law of effect'. The law of effect states that: the behaviour that is 
positively reinforced tends to be repeated, and behaviour that is not reinforced tends not to be repeated. Incentive motivation draws largely from this theory, that is, reinforcement theory provides the entry point for incentive motivation.

\section{Types of incentive schemes}

Generally, in incentive schemes are classified into two types: material incentive and non-material incentives. Material incentives according to Hongoro and Normand (2002), are those provided for specific group of workers to motivate them for a specific behaviour. Non-material (non-financial) incentive schemes on the other hand are directed at moral motivation to serve in the interest of the community. Non -material incentives to employee especially in the public service attract a certain kind of person that more readily identifies with the mission of the organization, Paul \& Marc (2007). Caruth (2000) however, classified incentives into individual incentives and group incentive schemes.

For this article, the following specific incentive programmes are relevant and open to organizations in Nigeria:

Cash incentives: This is payment for performance that meets established criteria. Employees are paid certain sum of money or savings bond. Successful suggestions, for example, are recognized with a sum of money equal to the fraction of the cost of the savings attributed to the suggestion.

Special benefits: This involves additional paid leave, commission, extraordinary performance, perfect attendance and so on.

Recognition: Employee recognition as an incentive, offer relatively low cost but high-impact means to reward to employees. This recognition could be done by holding annual dinners, luncheons, banquets etc at which highachievers or performers are celebrated. Other recognition techniques include the distribution of T-shirts, certificates and gold nameplates. Sometimes high performing employees are featured in organizational in house newsletters and in some cases are the subjects of press releases.

Special opportunities: Available records suggest that management in some organizations used special opportunities as incentive schemes. These special opportunities include the chance to experience special training favoured assignments, flexible working conditions, mentorship and so on.

Piece rate: Under this incentive scheme, a uniform price is paid per unit of production. Employees may therefore be compensated according to the number of pieces they produced or processed. Compensation is therefore directly proportional to the level of productivity or results obtained. The scheme is easy to calculate and employees may determine or predict their rewards in the short term and regulate their pace of work in accordance with the level of compensation they want to attain.

Commission: Used typically with sales people, commissions are incentive compensation based on a percentage of total sales. A good number of sales people work on a salary (base pay) plus commission. Others work on a straight commission basis only. Commission according to Armstrong (2003) is intended to act as an incentive, a reward and a means of recognizing achievement. A commission only incentive scheme provides a sales person for example, with incentive payment based on a percentage of the sales turnover they generate, while a base salary plus commission scheme provide for a proportion of total earnings to be paid in commission, and the rest in a fixed salary.

Profit Sharing: Profit sharing is an incentive compensation plan that results in the distribution of a predetermined percentage of the company's profits to employees. This plan is used to integrate the employee's interests with those of the company. It is the payment to eligible employees of sums in the form of cash or shares related to the profits of the company during a specified period of time.

Nwachukwu (2009) opines that the essence of profit sharing is to give employees a share in the company profits as recognition of their outstanding effort. Management decides on what percentage of company profit to be shared by employees. To act as a motivator, profit sharing may be closely tied to productivity. The profit to be shared may come once a year and when well administered, profit sharing acts as an incentive and helps to instill the spirit of common purpose. A profit sharing plan is designed to pay out incentives when the company is most able to afford it and it may come in the form of current distribution plan, deferred plan and combined plan.

Gain-sharing: Armstrong (2003) emphasizes that gain-sharing is a formula- based company or factory wide incentive plan that provides for employees to share in the financial gains resulting from increases in added value or another measure of productivity. Gain-sharing plans (also known as productivity incentives) generally refer to incentive plans that involve many or all employees in a common effort to achieve a company's productivity objectives. Gain-sharing formulae may include: The Scalon plan, the Rucker Plan, Improshare, Taylor Plan, Gantt Plan, and so on. The link between employee efforts and the payout can usefully be made exploit by involving them in analyzing results and identifying areas for improvements. Profit-sharing differs from gainsharing in that the former is based on more than improved productivity. Gain sharing aims to relate the payouts much more specifically to productivity and performance improvements within the control of employees. 
Golden handcuffs: Sometimes called retention or loyalty incentives, golden handcuffs are used by a company to retain talented employees by demonstrating that they are valued for their contributions and by working fairly and consistently. Golden handcuffs make it difficult and costly for an employee to leave the organization. Golden handcuff packages include share options for managers, high salary scale, and high retirement benefits. The standard established by this incentive scheme is too high for any other company to meet up. This is why the scheme is called 'golden or executive handcuff'; it ties the employee fully to the organization. This scheme is one of the recent incentives provided to employees in many private organizations in Nigeria.

Share Ownership: This plan intends to make employees co-owners of the company. It creates a provision for employees to have a stake in the company and longer term compensation by giving them options to buy shares at a future date for their current market price. Stock options are motivational to employees because they confer on employees the right to buy the company's stock at a specified price. Many organizations in Nigeria now motivate employees through the employee stock ownership approach.

\section{Purpose of incentive schemes in organizations}

According to Caruth, Middlebrook and Frank (1982), the general purpose of incentive schemes is to increase productivity in the organization. By relating compensation to output, an employer is attempting to induce workers to turn out a greater volume of work thereby lowering the cost of producing a single unit of output. Specifically, the purpose of incentives to both an employee and the organization is to:

- Improve motivation

- Tie pay to performance

- Recognize differences in employee performance

- Increase competition among employees

- Attract and retain productive employees

- Reduce absenteeism

- Reduce idle time

- Reduce or control costs

- Utilize equipment more effectively

- Relate increases in compensation to increases in productivity

- Avoid additions to employees

- Create uniform processing costs

- Direct efforts toward achieving organizational objectives and so on.

VIII. Caveats for administration of incentive schemes

Seemingly valid arguments exist against the administration of incentive schemes. Some experts argue that an incentive is an expense (a cost) to the organization. Others feel that incentives make employees to over comply. Notable among those against incentive plans is Kohn (2001). Kohn specifically identified many concerns of incentives, linked incentives to behavior modification problems and put forward the following arguments against incentive compensation:

Incentive punishes: Kohn argues that there are punitive features built into incentive schemes. According to him, when compensating employees management is also demonstrating control over them. This may eventually assume a punitive quality by making the recipient of incentive compensation feel subservient. Again, after giving incentives, employees come to expect the same or other form of compensation in the future. If their expectations are not met, they feel psychologically punished.

Incentive schemes rupture relationships: Kohn suggests that disparities in individual incentives create jealousies and unhealthy competition. In other words, incentive compensation usually leads to feelings of inequity because people invariably compare their rewards with others. Incentives also create a psychological distance between the person giving and receiving the incentive schemes package. Taken together, incentive disrupts the collaboration needed for effective organizational climate, learning, and understanding.

Incentive programmes ignore reasons: Employees need to spend time discovering the cause of behavior problems. However, Kohn felt that, instead, the use of incentives as 'quick fixes' especially where organizations use incentives for the most trivial reasons. This supports Nelson's (1994) argument that the causes of a bad behavior (problem) should be identified and appropriate solutions to that problem found out instead of splashing money on employees to force a solution to a problem or bad behaviour. In a situation like this, incentives are seen as ignoring reasons.

Incentive schemes discourage risk taking: Kohn cites evidence that though incentives motivate people, it motivates exactly what is necessary to get the reward and nothing more. Incentive programmes, according to Kohn, dampen creativity because employees no longer explore new opportunities outside the realm of 
compensated (rewarded) behavior or results. That is to say incentives motivate employees to get rewards, not to discover better ways to help the organization.

Incentive schemes undermine intrinsic motivation: According to Kohn, incentives 'kill' a persons' motivation found in the work itself. Intrinsic motivation related to fulfilling, for instance, growth needs, which are most powerful and sustaining sources of motivation. He argued further that employees are intrinsically motivated to perform a task after they had received an extrinsic incentive for performing it. The argument here concerned the risk of losing intrinsic motivation when extrinsic incentives are introduced.

\section{Conditions for effective use of incentive schemes}

Caruth (1986) stated that incentive schemes are not a panacea for an organizations productivity problems, not are they universally applicable to all types of work organizations. Effective use of incentives hinges upon a number of conditions. In general, these conditions are: the nature of work itself, control systems and the human responses to incentives. Specifically, the following are the conditions necessary for the administration of an effective incentive schemes:

- Direct relationship between effort and output.

- Readily identified units of output

- Even and continuous work flow

- Standards of performance

- Quality standards

- Measurement systems

- Opportunity for cost reduction

- A good unit cost system

- Sufficient financial inducement

- Reasonable time spans for payment

- Reliable stable technology

- Selective application

- Top management commitment

\section{Methodology/approach}

The objective of the paper is achieved by drawing largely on the use of previous research findings and cases to demonstrate the need for and to analyze incentive schemes as an important factor in determining employee motivation and productivity in organizations. The paper adopts the United Nations Development Programme (UNDP) 2006 premise on incentive systems: incentive motivation and development performance where research findings and cases were cited to examine how incentives have high positive linkages to employee motivation and productivity.

\section{X. $\quad$ Research cases and findings}

Some of the research findings and cases from public organizations relevant to this paper are as presented below:

From "Top-Ups" to sustainable incentives for civil servants (Tanzania): The government of Tanzania and donors came together to institutionalize a system of public service incentives through "The Selected Accelerated Salary Enhancement Scheme (SACE)". SASE offered a potentially sustainable solution to salary incentive problems within the wider context of pay reform. The aim was to address the issue of low motivation, uncompetitive salary structures and constraints on capacity development. The target of SASE was employees with the greatest impact on service delivery. The result was that SASE provided a sustainable solution to the issue of salary incentives.

Another case is that of "The Rwanda Revenue Authority's incentives to perform". This case provides an insight into the role that non-material incentives can play in mobilizing capacity and performance. This demonstrates the fact that while pay has been and will remain an important driver of performance; experience shows how important other motivators too have been at both the individual and organizational level. The RRA was established to administer the collection of taxes, and custom \& excise duties on behalf of government. The RRA was able to transform from a non-performing government department into a performing and respected organization. Research findings indicated an increase in revenue from $9-13 \%$ of GDP, while the costs of collection also decreased. Corruption levels significantly reduced and the general standing of the organization improve dramatically. Some of the non-material incentives that played important roles included: a clear mandate, agency status, management autonomy, corporate values and reputation, effective human resource management, client focus and so on. These non-material incentives also spurred change processes.

Lastly, "The "Bolsa Escola' helps mothers send children to school" in Brazil is also a good case of incentive scheme. Under this scheme, the Brazilian government, through its municipalities, offers mothers a 
stipend for enrolling and keeping their children in school. The incentive has inspired strong commitment among parents. The Bolsa Escola (school stipend) National Programme is intended to give a monthly sum to families with income lower than about $\$ 30$ per person and whose children in the age of $6-15$ attended primary school. A stipend of $\$ 6$ is made for each child on condition that the child attends a minimum of $85 \%$ of classes. The result was dramatic in terms of school enrolment, attendance, and community participation. Furthermore, this incentive scheme is recognized as playing a fundamental role in retaining children at school and thus democratizing education in Brazil. Bolsa Escola now benefits over 5 million families and more than 8 million children.

\section{XI. $\quad$ Findings}

Based on the above literature review and case analyses, the paper found out that there is a link between incentive schemes and employee motivation and productivity. Incentive schemes, if properly designed and administered, do motivate employees and increase their productivity in organizations. The paper also revealed that a number of incentives do exist in some organizations in Nigeria. They include the following:

- Pay, salaries, wages, allowances, etc.

- Direct financial benefits, such as pension, illness/health/life insurance, allowances (clothing, housing, etc), subsidies, gain sharing.

- Indirect financial benefits - subsidized meals/clothing/accommodation/transport, scholarships, tax breaks, and deferred compensation such as seniority pay.

- Flexible schedules, part-time/temporary work, sabbatical, study leave, holidays, vacation, etc.

- Work environment/conditions, occupational health, safety, recreational facilities.

- Amenities, school access, infrastructure, transport, etc.

- Job security, career/professional development/ training opportunities.

- Feedback, coaching, valued by organization.

- Solidarity, socializing, camaraderie, affection, passion.

- Status, prestige, recognition.

- Sense of duty, purpose, mission.

- Security, opportunities, stability, and risk.

If these incentives are properly administered, it is hoped that employees would be motivated and increase their productivity in the organization.

\section{Conclusion and recommendations}

Incentive schemes are fast becoming increasingly a popular technique in attracting, motivating, developing, and retaining employees in organizations in Nigeria. Experience has shown that organizations that provide effective incentives are more likely to have satisfactory job performance from employees. From the reviews, the major conclusion to the drawn is that incentive schemes do have significant correlation with employee motivation and productivity in organizations in Nigeria.

Finally, the paper recommends that:

- Management should identify the type of incentive scheme that is most motivating to employees. This should also be based on individual differences and needs.

- The incentives must be feasible for the organization to implement. Organizations should therefore try to balance material considerations with non-material reinforcements to maximize job quality and quantity.

- Management should seek and obtain feedback on how employees perceive incentives. Feedback combined with appropriate incentive schemes produce the strongest effect on job productivity.

- Performance goals should be clearly defined. The goals should be specific measurable, achievable, and time bounded. Productivity cannot easily be assessed if what constitutes productivity is not clearly and objectively defined at the onset.

\section{References}

[1]. Adekoya, A. (1987). The Role of Government in Promoting Increased Productivity on Nigerian Farms: Proceedings of a National Conference on Productivity, Abuja.

[2]. Agoro, R. O. (1991). Productivity, the Panacea to Industrial Growth, Economic Fertility and National Greatness. Proceedings of a National Conference on Productivity, Abuja.

[3]. Armstrong, M. (2003). A handbook of Human Resource Management. 9th edition, London: Kogan Page.

[4]. Baron, R.A. (1991). Motivation in Work Settings: Reflections on the Core of Organizational Research. Motivation and Emotion Vol. 15 No 1, 240.

[5]. Buchanan, D. \& Huczynski, A. (2004). Organizational Behaviour: An Introductory Text. London: Prentice Hall.

[6]. Campbell, J. P. (1990). Modeling the Performance Prediction Problem in Industrial and Organization Psychology in A Handbook of Industrial and Organizational Psychology Impact and Evaluation. London: IPM. 
[7]. Caruth, C. D. (1986). Compensation Management for Banks Boston: Bankers Publishing

[8]. Caruth, D. L., Middlebrook, B. Frank, R. (1982). "Performance Appraisals: Much more than Once a Year Task", Supervising Management, September p. 28-36

[9]. Cherrington, D. J. (1995). The Management of Human Resources (4th ed). Englewood Cliffs, New Jersey: Prentice Hall.

[10]. Drucker, P. (1974). Management: Tasks, Responsibilities and Practices. London: Heinemann.

[11]. Griffin, R. W. \& Ebert, R. J. (1993). Business. (3rd ed). Englewood Cliffs: Prentice Hall.

[12]. Hartman, R. J., Kurtz, E. M. \& Moses, E. K. (1994). Synthesis of Transit Practice 3: Incentive programs to improve transit employee performance. New York: National Academy Press.

[13]. Hongoro, C. \& Normand, C, (2002).Health Workers: Building and Motivating the Workforce.

[14]. ILO (1985). Flexible Working Time in Production, Social and Labour Bulletin, Geneva.

[15]. Kohn, A. (2002) Why Incentive Plans cannot work? Harvard Business Review on Compensation 96-108.

[16]. Krech, D., Crutchfield, R. S. \& Ballachey, E. L (1962). Individual in Society. New York: McGraw Hill.

[17]. Mitchell, T.R. (1982). Motivation: New Directions for Theory, Research and Practice. Academy of Management Review Vol. 7 No. 1 January. 24-27.

[18]. Nwachukwu, C. C. (2009). Human Resource Management (3rd ed) New Owerri, Springfield Publishers Ltd.

[19]. Nwasike, J. (1991). Increasing Productivity in the Nigerian Public Sector. Proceedings of a National Conference on Productivity, Abuja.

[20]. Paul, E. \& Marc, R. (2007). "Performance Budgeting, Motivation and Incentives" in "Performance Budgeting: Linking funding and results". Washington DC: International Monetary Fund.

[21]. Prokopenko, J. (1992). Productivity Management: A Practical handbook. Geneva: International Labour Office.

[22]. Skinner, B. F. (1974). About Behaviourism. London: Cape Publishers

[23]. U.N.D.P. (2006). Incentive Systems: Incentives, motivations, and development performance. Capacity building Resource, Conference Paper No. 8 .

[24]. Udo-Aka, U (2003). Measuring Productivity: Issues and problems in productivity in Nigeria. Proceedings of National Conference on Productivity, NISER. 